\title{
How is quality of cardiopulmonary resuscitation being assessed? A national survey of Canadian emergency medicine physicians
}

\author{
Natasha Wright, $\mathrm{MD}^{*}$; Yiqun Lin, $\mathrm{MD}, \mathrm{PhD}^{\dagger}$; Adam Cheng, $\mathrm{MD}^{\ddagger}$

\section{CLINICIAN'S CAPSULE} \\ What is known about the topic? \\ Feedback on the quality of cardiopulmonary resuscitation \\ (CPR) during cardiac arrest is a critical component for the \\ delivery of high-quality CPR. \\ What did this study ask? \\ How are Canadian emergency physicians assessing the \\ quality of CPR, and what are barriers to implementation \\ of feedback devices? \\ What did this study find? \\ CPR quality is frequently assessed using inaccurate meth- \\ (67.4\%). This was followed by real-time pulse check $(29.7 \%)$ \\ and end-tidal $\mathrm{CO}_{2}$ values (21.7\%). Only $12 \%$ of physicians uti- \\ lized CPR feedback technology. The most common perceived \\ barrier to utilization was unavailability, inexperience with \\ devices and lack of guidelines/evidence for their use. \\ Conclusion: Most Canadian emergency physicians that \\ responded to our survey, assess quality of CPR by standing \\ at the foot of the bed and utilize visual observation and palpa- \\ tion methods which are known to be inaccurate. A minority \\ utilize objective measurements such as $\mathrm{ETCO}_{2}$ or feedback \\ devices, with the greatest barrier being lack of availability.
} ods, and only a minority of clinicians use feedback technology because of a lack of availability.

Why does this study matter to clinicians?

Clinicians should recognize inaccurate methods of assessing CPR quality and implement more objective methods such as feedback devices to improve resuscitation care.

\section{ABSTRACT}

Background: High-quality cardiopulmonary resuscitation (CPR) is a fundamental intervention for cardiac arrest, yet health care providers rarely adhere to recommended guidelines. Real-time feedback improves CPR performance. It is currently unknown how Canadian emergency physicians assess CPR quality during cardiac arrest and if they use feedback devices. Our aim was to describe how emergency physicians assess CPR quality and to describe eventual barriers to implementation of feedback technology.

Methods: This was a cross-sectional survey that was distributed to attending and resident emergency physicians through the Canadian Association of Emergency Physicians. Responses were summarized and analyzed using descriptive statistics.

Results: The response rate was 19\% (323/1735). Visual observation was the most common method of assessing CPR quality $(41.2 \%)$, with leaders standing at the foot of the bed

\section{RÉSUMÉ}

Contexte: Il est crucial d'effectuer des manœuvres de réanimation cardiopulmonaire ( $\mathrm{RCP})$ de qualité dans le traitement des arrêts cardiaques; pourtant, rares sont les fournisseurs de soins qui respectent les lignes directrices recommandées. Les rétroactions en temps réel améliorent l'efficacité des manœuvres de RCP. Toutefois, on ne sait pas comment les urgentologues au Canada évaluent la qualité des RCP durant les arrêts cardiaques et s'ils utilisent des dispositifs de rétroaction. L'étude visait donc à établir la manière dont les urgentologues évaluent la qualité des RCP et à faire ressortir de possibles obstacles à l'utilisation de la rétroaction technologique.

Méthode: Il s'agit d'une enquête transversale menée par l'Association canadienne des médecins d'urgence, parmi les urgentologues traitants et les résidents dans le domaine. Les chercheurs ont d'abord résumé les réponses, puis analysé les données à l'aide de statistiques descriptives.

Résultats: Le taux de réponse a atteint $19 \%$ (323/1735). La méthode d'évaluation la plus courante de la qualité des manœuvres de RCP reposait sur l'observation visuelle $(41,2 \%)$ faite au pied du lit par les chefs d'équipe $(67,4 \%)$. Suivaient la vérification du pouls en temps réel $(29,7 \%)$ et les valeurs de $\mathrm{CO}_{2}$ en fin d'expiration $(21,7 \%)$. Enfin, seuls $12 \%$ des médecins avaient recours à la rétroaction technologique sur la RCP.

\footnotetext{
*Department of Emergency Medicine, Cumming School of Medicine; University of Calgary, Calgary, AB; †Department of Community Health Sciences; Cumming School of Medicine; University of Calgary, Calgary, AB; and the $¥$ Departments of Pediatrics and Emergency Medicine, Cumming School of Medicine; University of Calgary, Calgary, AB.
}

Correspondence to: Dr. Natasha Wright, Department of Emergency Medicine, Foothills Medical Centre, Room C231, 1403-29 Street NW, Calgary, AB T2N 2T9; Email: wright.tash@gmail.com

(c) Canadian Association of Emergency Physicians 
Les obstacles évoqués le plus souvent étaient le manque de dispositifs, le manque d'expérience d'utilisation de ces appareils et le manque de lignes directrices sur leur emploi ou de données probantes à l'appui.

Conclusion: La plupart des urgentologues au Canada qui ont participé à l'enquête évaluent la qualité des manœuvres de $\mathrm{RCP}$ en se tenant au pied du lit et en se fondant sur l'observation visuelle et la palpation, deux méthodes connues pour leur inexactitude. Les autres, soit la minorité, ont recours à des mesures objectives comme la pression de $\mathrm{CO}_{2}$ en fin d'expiration ou à des dispositifs de rétroaction, et le plus grand obstacle perçu est le manque d'appareils.

Keywords: Cardiac arrest, emergency medicine, resuscitation

\section{BACKGROUND}

In Canada, approximately 40,000 cardiac arrests occur annually. ${ }^{1}$ The survival rate is variable, ranging from $3 \%-35 \% .^{2}$ High-quality cardiopulmonary resuscitation (HQ-CPR) is an essential skill and has been shown to improve survival. ${ }^{3}$ Despite this, studies show that health care providers struggle to provide guideline-compliant CPR during cardiac arrests. ${ }^{2}$ CPR feedback devices have provided a means of delivering objective feedback on the quality of chest compressions during cardiac arrest. $^{2}$ Improved CPR performance through the use of devices in training and clinical care have the potential to improve patient outcomes. ${ }^{2,3}$ Currently, it is unclear how emergency physicians (EPs) are assessing chest compression quality and if feedback devices are being utilized. In this study, we aimed to describe current practices of monitoring CPR quality during cardiac arrest, to determine if Canadian EPs are using CPR feedback devices, and to identify eventual barriers to their implementation.

\section{METHODS}

\section{Study design}

We conducted a national survey to determine current practices of assessing CPR quality during cardiac arrests in the emergency department (ED). Ethics approval was obtained from the University of Calgary Conjoint Health Research Ethics Board. Consent was implied upon participation in the survey.

\section{Study setting and population}

In this cross-sectional study, an online survey was administered to physician members of the Canadian Association of Emergency Physicians (CAEP) over a six-week period between September and October 2016. Three emails were sent at two-week intervals to all participants to serve as reminders for survey completion. Pediatric EPs were excluded. The denominator of EPs at the time of distribution was 1,735 .

\section{Survey content}

After a literature review, survey questions were developed that targeted our objectives. The majority of questions were multiple choice with an option for comments. Pilot testing of the survey was conducted in an independent group of EPs to ensure the clarity of questions and were modified accordingly. Pilot survey data were excluded. SurveyMonkey ${ }^{\mathrm{TM}}$ was utilized for distribution and data collection.

\section{Statistical analysis}

Data were exported to Microsoft Excel (2018, Version 16.23). Responses were summarized and analyzed using descriptive statistics.

\section{RESULTS}

The total response rate was $19 \%(323 / 1,735)$. The survey was sent to 1,743 recipients with eight email bounce backs and eight mistakenly sent to registered nurses who were excluded, making 323 the final number of surveys analyzed. The majority of respondents were geographically located in Ontario (43.3\%), Quebec (12.2\%), and British Columbia (12.9\%). See Table 1 for respondent characteristics.

\section{Current state of CPR assessment}

Physician team leaders were most commonly responsible for evaluating CPR quality (310/465). A second physician 


\begin{tabular}{|c|c|c|c|}
\hline Characteristic & $\begin{array}{c}\text { Total sample } \\
n(\%)\end{array}$ & $\begin{array}{c}\text { Physicians } \\
n(\%)\end{array}$ & $\begin{array}{c}\text { Residents } \\
n(\%)\end{array}$ \\
\hline \multicolumn{4}{|l|}{ Gender $(n=305)$} \\
\hline Male & $188(61.6)$ & $162(62.1)$ & $26(59.1)$ \\
\hline Female & $117(38.3)$ & 99 (37.9) & $18(40.9)$ \\
\hline \multicolumn{4}{|l|}{ Practice setting $(n=305)^{*}$} \\
\hline Tertiary Care ED & $182(60.0)$ & $144(50.7)$ & $38(86.4)$ \\
\hline Community ED >30,000 & 99 (32.8) & $95(33.5)$ & $4(9.1)$ \\
\hline Community ED <30,000 & $47(15.4)$ & $45(15.8)$ & $2(4.5)$ \\
\hline \multicolumn{4}{|l|}{ Training background $(n=306)$} \\
\hline CCFP & $32(10.5)$ & $29(10.6)$ & 7 (15.9) \\
\hline CCFP(EM) & 122 (39.9) & $118(43.1)$ & $4(9.1)$ \\
\hline FRCPC & $135(44.1)$ & $102(37.2)$ & $33(75.0)$ \\
\hline Other $^{\dagger}$ & $17(5.6)$ & $13(4.2)$ & $2(0.7)$ \\
\hline \multicolumn{4}{|l|}{$\begin{array}{l}\text { Number of years of ED } \\
\text { experience }(n=304)\end{array}$} \\
\hline$<1$ year & $23(7.6)$ & $17(6.5)$ & $6(13.6)$ \\
\hline $1-5$ years & $94(30.9)$ & $56(21.5)$ & $38(86.4)$ \\
\hline $6-10$ years & $45(14.8)$ & 45 (17.3) & $0(0.0)$ \\
\hline $11-20$ years & $71(23.4)$ & $71(27.3)$ & $0(0.0)$ \\
\hline$>20$ years & $71(23.4)$ & $71(27.3)$ & $0(0.0)$ \\
\hline \multicolumn{4}{|l|}{$\begin{array}{l}\text { Percent of clinical practice } \\
\qquad(n=306)\end{array}$} \\
\hline$<25 \%$ & $16(5.2)$ & $13(4.9)$ & $3(6.8)$ \\
\hline $25 \%-50 \%$ & $22(7.2)$ & $21(8.0)$ & $1(2.2)$ \\
\hline $50 \%-75 \%$ & $64(20.9)$ & $58(22.1)$ & $6(13.6)$ \\
\hline$>75 \%$ & $204(66.7)$ & $170(64.8)$ & 34 (77.3) \\
\hline \multicolumn{4}{|l|}{$\begin{array}{l}\text { Number of cardiac arrests } \\
\text { involved in per month } \\
(n=306)\end{array}$} \\
\hline$\leq 1$ & $158(51.6)$ & $131(50.0)$ & $27(61.4)$ \\
\hline $2-5$ & $137(44.8)$ & $121(46.1)$ & $16(36.4)$ \\
\hline$>5$ & $11(3.6)$ & $10(3.8)$ & $1(2.3)$ \\
\hline \multicolumn{4}{|l|}{ ACLS up to date $(n=305)$} \\
\hline Yes & $210(68.9)$ & 172 (65.9) & 38 (86.3) \\
\hline No & $95(31.2)$ & 89 (34.0) & $6(13.6)$ \\
\hline \multicolumn{4}{|l|}{$\begin{array}{l}\text { Department mandate/ } \\
\text { subsidize ACLS? }(n=307)\end{array}$} \\
\hline Yes & $128(41.7)$ & 98 (37.3) & $30(68.2)$ \\
\hline No & $137(44.6)$ & $133(50.6)$ & $4(9.1)$ \\
\hline Unsure & $42(13.7)$ & $32(12.2)$ & $10(22.7)$ \\
\hline \multicolumn{4}{|c|}{$\begin{array}{l}\text { ACLS = Advanced Cardiovascular Life Support; } C \text { CFP }=\text { Canadian College of Family } \\
\text { Physicians; CCFP(EM) = Canadian College of Family Physicians Emergency Medicine; } \\
\text { ED = Emergency Department; FRCPC = Fellow of the Royal College of Physicians of } \\
\text { Canada. } \\
\text { *Some respondents worked at multiple practice settings. Respondents may have also } \\
\text { skipped various questions, which is why } n \text { is variable for different characteristics. } \\
\text { tCritical care, FACEP (Fellow of the American College of EM), ABEM (American Board of } \\
\text { EM), CSPQ (Certificat de Spécialiste de la Province de Québec), FRCPC-other, MD, R2, } \\
\text { Surgical internship, pre-specialty era (1983). } \\
\text { Of note: Total number of residents numbered } 44 \text {. For this question, a few respondents } \\
\text { typed in family medicine resident but skipped previous question of PGY resident status, } \\
\text { which is why the total number is different. }\end{array}$} \\
\hline
\end{tabular}

(55/465) or a bedside nurse (61/465) also evaluated CPR quality (55/465). Rarely, a respiratory therapist was responsible for CPR assessment (27/465). Only $12.1 \%$ (38/315) of those surveyed use feedback devices to assess CPR quality. Visual assessment $(41.2 \% ; 133 / 323)$ and pulse check $(29.7 \%$; 96/323) were the most common methods of assessing CPR quality (see online supplementary materials, eFigure 1). Regarding ventilation (38.3\%; $118 / 308$ ) were observed for rate and volume, with $58.8 \%$ (188/320) using direct visual observation.

When the team leader oversaw the CPR quality assessment, most, $67.4 \%$ (217/322), stood at the foot of the bed, $25.8 \%(83 / 322)$ preferred the side, and $5.0 \%$ $(16 / 322)$ preferred the head of the bed.

\section{Opinions on feedback devices}

The majority of those surveyed $(72.3 \% ; 227 / 314)$ believed that feedback devices are needed as part of care in the ED. A minority $(12.1 \% ; 38 / 315)$ utilized CPR feedback devices as part of clinical practice.

\section{Perceived barriers to feedback devices}

Multiple reasons were identified as to why respondents did not utilize CPR feedback devices (see online supplementary materials, eFigure 2). If resources/funding were readily available, $87.2 \%(273 / 313)$ of respondents said they would use them. When asked to explain why they would not use feedback devices, even if available, $40.4 \%$ (17/42) mentioned a lack of evidence, and $28.6 \%(12 / 42)$ did not think there was an added benefit to the interventions they already provide.

\section{DISCUSSION}

The 2015 Heart and Stroke Foundation of Canada resuscitation guidelines recognize audiovisual feedback devices as a tool that may be used for optimization of CPR performance. ${ }^{4}$ Use of feedback devices has demonstrated improvement in CPR quality for both in- and out-of-hospital cardiac arrest. ${ }^{3}$ Evidence suggests that increasing chest compression depth is a predictor of achieving return of circulation (ROSC) and improved short term survival. ${ }^{5}$ Observational studies utilizing 
porcine models have shown an association between feedback-directed chest compressions and survival. ${ }^{6}$ However, survival benefit in humans attributed to the use of feedback devices remains inconclusive.,

Our survey found that most respondents assess quality of CPR by visual assessment. A study of health care providers found that the overall accuracy of visually assessing CPR quality was $65.6 \%{ }^{8}$ Accuracy improved when viewed from the side $(70.8 \%)$ compared with the usual foot of the bed $(68.8 \%) .{ }^{8}$ Another study found a large discrepancy if comparing visual assessment of CPR quality with objective data collected by manikins. ${ }^{9}$ To optimize the accuracy of assessment, it may also be beneficial to delegate a "CPR coach" who assesses compressions from the side of the bed.

The second preferred way to assess CPR quality was real-time pulse check. The United Kingdom Resuscitation Council recommends against using carotid or femoral pulses to evaluate the quality of chest compressions. ${ }^{10}$ A pulse found in the femoral region may be of venous origin rather than arterial. ${ }^{11}$ Our survey demonstrates a common practice that is inaccurate, highlighting a need for further education and better use of tools to give more accurate feedback on CPR quality.

Aside from feedback devices, end-tidal $\mathrm{CO}_{2}\left(\mathrm{ETCO}_{2}\right)$ monitoring was one of the least common methods of monitoring CPR quality in our study. Studies have shown an association between $\mathrm{ETCO}_{2}$ levels and outcome, particularly in the first 20 minutes. High levels $(>20 \mathrm{~mm} \mathrm{Hg}$ ) are associated with increased survival, and very low levels $(<10 \mathrm{~mm} \mathrm{Hg})$ are associated with increased mortality. ${ }^{4}$ Factors such as initial rhythm, bystander CPR, duration of arrest, and use of bicarbonate influence $\mathrm{ETCO}_{2}$ values, confounding the interpretation of capnography during CPR. Guidelines recommend a titration of CPR performance to a goal of $>20 \mathrm{~mm} \mathrm{Hg}$. However, the relationship among $\mathrm{ETCO}_{2}$, compression depth, rate, and fraction is unclear. $^{2,6}$

\section{Identified barriers}

One of the main barriers was the lack of availability of feedback devices and resultant unfamiliarity with its clinical use. The common theme underpinning this barrier seems to be the perceived lack of benefit and adequacy of current care.

\section{Limitations}

Our study had several limitations. Our response rate was $19 \%$ that limits our ability to accurately describe current practice. We surveyed CAEP members, so we might have missed a large proportion of EPs in Canada. Additionally, the practice described cannot be translated outside the ED. There might also have been a clustering effect in which individuals in certain institutions or provinces practice similarly. There is potential for sampling bias as ED physicians interested in this topic or those who hold strong views for or against feedback devices might have been overrepresented. It is also possible that the design of our survey might have influenced how participants responded.

\section{CONCLUSION}

Among the Canadian EPs who responded to our survey, only a minority use feedback devices to assess quality of CPR during cardiac arrest. The majority of respondents assess quality of CPR by standing at the foot of the bed and utilize visual assessment and palpation methods that are notoriously inaccurate. The primary barrier to feedback device use was the unavailability in the ED.

\section{SUPPLEMENTARY MATERIAL}

The supplementary material for this article can be found at https://doi.org/10.1017/cem.2019.382

Competing interests: The authors have nothing to disclaim. There are no conflicts of interest. This research received no specific grant from any funding agency, commercial, or not-for-profit sectors.

\section{REFERENCES}

1. Heart and Stroke Foundation. Statistics. Available at: http:// www.heartandstroke.com/site/c.ikIQLcMWJtE/b.3483991/ k.34A8/Statistics.htm (accessed March 13, 2017).

2. Meaney PA, Bobrow BJ, Mancini ME, et al. Cardiopulmonary resuscitation quality: improving cardiac resuscitation outcomes both inside and outside the hospital: a consensus statement from the American Heart Association. Circulation 2013;128(4):417-35.

3. Hostler D, Everson-Stewart S, Rea TD, et al. Effect of real-time feedback during cardiopulmonary resuscitation 
outside hospital: prospective, cluster randomised trial. BMF 2011;342:d512.

4. 2015 Heart and Stroke Foundation of Canada Resuscitation Guidelines. Available at: https://eccguidelines.heart.org/ index.php/circulation/cpr-ecc-guidelines-2/ (accessed March 13, 2017).

5. Talikowska M, Tohira H, Finn J. Cardiopulmonary resuscitation quality and patient survival outcome in cardiac arrest: A systematic review and meta-analysis. Resuscitation 2015;96:66-77.

6. Chopra AS, Wong N, Ziegler CP, Morrison LJ. Systematic review and meta-analysis of hemodynamic-directed feedback during cardiopulmonary resuscitation in cardiac arrest. Resuscitation 2016;101:102-7.

7. Kirkbright S, Finn J, Tohira H, et al. Audiovisual feedback device use by health care professionals during CPR: a systematic review and meta-analysis of randomized and non-randomized trials. Resuscitation 2014;85(45):460-71.

8. Jones A, Lin Y, Nettel-Aguirre A, Gilfoyle E, Cheng A. Visual assessment of CPR Quality during pediatric cardiac arrest: does point of view matter? Resuscitation 2015;90:50-5.

9. Gonzalez BS, Martinez L, Cerda M, et al. Assessing practical skills in cardiopulmonary resuscitation: discrepancy between standard visual evaluation and a mechanical feedback device. Medicine (Baltimore) 2017;96(13):e6515.

10. Gwinnutt C, Davies R, Soar J. In-hospital resuscitation. Resuscitation Council UK. 2015 guidelines update; 2015. Available at: https://www.resus.org.uk/resuscitation-guidelines/in-hospital-resuscitation/ (accessed March 13, 2017).

11. Connick M, Berg RA. Femoral venous pulsations during open chest cardiac massage. An Emerg Med 1994;24(6):1176-9. 